\title{
$P M L$ silencing inhibits cell proliferation and induces DNA damage in cultured ovarian cancer cells
}

\author{
SHENG-BING LIU, ZHONG-FEI SHEN, YAN-JUN GUO, LI-XIAN CAO and YING XU \\ College of Medicine, Jiaxing University, Jiaxing, Zhejiang 314001, P.R. China
}

Received April 28, 2017; Accepted May 17, 2017

DOI: $10.3892 /$ br.2017.919

\begin{abstract}
The promyelocytic leukemia $(P M L)$ gene is a tumor suppressor gene. It was first identified in acute promyelocytic leukemia, in which it is fused to retinoic acid receptor $\alpha$ by the $(15 ; 17)$ chromosomal translocation. The function of the PML protein is frequently lost or aberrant in human solid tumors. In human ovarian carcinoma tissue, PML detected by immunohistochemistry was highly expressed. A $P M L$-silencing vector, pSRG-shPml, was constructed and used to transfect human ovarian cancer cells. Cells were cultured and selected with puromycin for 10-15 days, and then the PML mRNA expression levels were detected by RT-qPCR and immunofluorescence. Proliferation and clone number of PML-depleted cells were detected using MTT assay and colony-forming assay. The protein expression associated with DNA damage and apoptosis was assessed in PML-depleted cells using western blot analysis and immunofluorescence. The results showed that PML was highly expressed in human ovarian tissue. The proliferation and colony formation of ovarian cancer cells were significantly inhibited after PML was depleted. Western blot analysis and immunofluorescence revealed that $\mathrm{p}-\mathrm{H} 2 \mathrm{AX}$ and cleaved caspase-3 expression significantly increased after $P M L$ silencing. PML was located in the nucleus, and it formed foci after X-ray irradiation. PML foci increased significantly with increasing irradiation doses.
\end{abstract}

\section{Introduction}

Promyelocytic leukemia protein (PML; also known as TRIM19) belongs to the family of tripartite motif (TRIM) proteins (1). The PML gene, which was found in the majority of acute promyelocytic leukemia, was first noted at the breakpoint of the $\mathrm{t}(15 ; 17)$ chromosomal translocation (2). PML is mainly expressed in the nucleus, where it forms dynamic structures known as PML nuclear bodies (PML-NBs). PML-NBs recruit

Correspondence to: Dr Ying Xu, College of Medicine, Jiaxing University, 56 South Yuexiu Road, Jiaxing, Zhejiang 314001, P.R. China

E-mail: xuyingmrd@163.com

Key words: apoptosis, ovarian neoplasms, DNA damage, leukemia many other proteins. A plethora of proteins have been shown to be recruited by PML within PML-NBs, either permanently, such as the death domain-associated protein (Daxx), SP100, and SUMO, or transiently, such as the p53 or CAMP response element-binding protein. PML-NBs are involved in many cell processes, including cell cycle progression, DNA damage response, transcriptional regulation, and apoptosis $(3,4)$. PML is reported to retain functionally critical oncogenic properties and to play a key role in leukemogenesis (5). It mediates several complex downstream signaling pathways. The determinant function of PML in tumorigenesis and cancer progression has kindled research interest in determining its involvement in many types of cancer.

Human PML can regulate alternative splicing through a variety of transcripts. These isoforms have the same identical $\mathrm{N}$-terminal region containing the ring, B-box, and coiled-coil motif but differ in their C-termini (6). In PML-NBs, PML has proved to be the organizing center, taking responsibility for recruiting various proteins via mechanisms involving SUMO modifications and interactions (7). The best-known posttranslational modification of PML is sumoylation, whereby PML directly binds SUMO and the SUMO-conjugating enzyme (8). Sumoylation of PML is necessary for the formation of PML-NBs because a PML mutant that cannot be modified by SUMO fails to recruit classical PML-NB components such as SP100, a protein involved in transcriptional regulation, and DAXX, a transcriptional repressor (9). PML is an important factor in the regulation of p53-dependent and p53-independent apoptotic pathways, and DAXX pro-apoptotic or anti-apoptotic activity in the PML-NBs may be cell-type specific (10). CCAAT/enhancer-binding protein $\beta$ is negatively regulated by the transcriptional co-repressor Daxx (11). A variety of regulatory factors is located in PML-NBs, and PML plays an important role in apoptosis regulation, for example, findings show that cells from PML-deficient mice reveal severe apoptotic defects (12). However, the role of PML with regard to proliferation, apoptosis, and DNA damage in ovarian cancer cells remains to be determined.

Therefore, we investigated the effect of PML on growth, clone formation and DNA damage in ovarian cancer cells.

\section{Materials and methods}

Reagents and cell culture. The ovarian cell line OV2008 was purchased from the American Type Culture Collection 
(CRL-1740; Rockville, MD, USA). At $37^{\circ} \mathrm{C}$ in a humidified $5 \% \mathrm{CO}_{2}$ incubator, the OV2008cells were cultured in DMEM medium (Invitrogen Life Technologies, Carlsbad, CA, USA) containing $10 \%$ fetal bovine serum (FBS; Hyclone, Logan, UT, USA) and $1 \%$ penicillin/streptomycin solution (Invitrogen Life Technologies). Cells seeded at the same density and cultured at the same time in complete medium were used as the control.

Plasmids and RNA interference. For the construction and identification of the pSRG-short hairpin RNA (shRNA) expression vector, sense and antisense strands of shRNA were produced. The $100 \mu 1$ reaction mix contained nuclease-free sterile water, $20 \mu \mathrm{l}$ annealing buffer (Biyuntian, Shanghai, China), and $20 \mu \mathrm{l}$ each of $50 \mu \mathrm{M}$ shRNA sense and antisense strands. The annealing conditions were: $95^{\circ} \mathrm{C}$ for $2 \mathrm{~min}$, followed by a decreasing temperature gradient of $1^{\circ} \mathrm{C}$ per $90 \mathrm{sec}$ until $25^{\circ} \mathrm{C}$. Annealing products were stored at $-20^{\circ} \mathrm{C}$. The pSRG empty vector $(1 \mu \mathrm{g})$ was treated with the enzymes SalI and $B g l \mathrm{II}$ separately at $37^{\circ} \mathrm{C}$ for $3 \mathrm{~h}$. The digestion products were electrophoresed, and the shRNA was incubated with the digestion products The products were transformed by DH5 $\alpha$ competent cells at $16^{\circ} \mathrm{C}$ overnight, coated on LB plates containing Amp resistance, and cultured overnight at $37^{\circ} \mathrm{C}$ for 8-10 h to generate monoclonal colonies. The bacterial liquid was then collected and subjected to rapid plasmid miniprep DNA extraction. The plasmids were digested with $X h o I$ and $E c o R I$, and the digested products were sent to Beijing Dingguo Biotechnology (Beijing, China) for sequencing. Subsequently, the cells were transfected with these plasmids.

$P M L$-knockdown ovarian cancer cell lines. Cells were transfected with $2 \mu \mathrm{g}$ of pSRG-shCon or pSRG-shPml plasmids using $200 \mu 1$ solution A (Opti-MEM) in each 60-mm dish. This was followed by incubation at room temperature for 5 min. Solution B $\left(6 \mu 1\right.$ Lipofectamine $^{\circledR} 2000$ and $200 \mu 1$ Opti-MEM) was added and incubated at room temperature for $5 \mathrm{~min}$. Solutions A and B were then mixed and incubated at room temperature for $30 \mathrm{~min}$. The mixture was added to the 6 -well plates $6 \mathrm{~h}$ after transfection, and the cell culture medium was replaced with normal medium. The cells were cultured with puromycin $(1 \mu \mathrm{g} / \mathrm{ml})$ for 7-10 days and were selected by EGFP fluorescence.

$R T-q P C R$. Total RNA was extracted from PML-knockdown ovarian cancer cells using TRIzol reagent (Invitrogen Life Technologies). cDNA was produced as per the manufacturer's protocols (Bio-Rad, Hercules, CA, USA), and the total RNA was reverse transcribed. The primers used were: $\beta$-actin: 5'-GCTCTTTTCCAGCCTTCCTT-3' and 5'-GTACTTGCGC TCAGGAGGAG-3'; PML: 5'-GCTGACCCCCAAGCAGA AGA-3' and 5'-CTCAGAAAGCTGAGGAAGTGCTG-3'. RT-qPCR conditions used were: $50^{\circ} \mathrm{C}$ for $5 \mathrm{~min}$; denaturation at $95^{\circ} \mathrm{C}$ for $5 \mathrm{~min}$; and 30 cycles of $95^{\circ} \mathrm{C}$ for $30 \mathrm{sec}, 60^{\circ} \mathrm{C}$ for $32 \mathrm{sec}$, and $72^{\circ} \mathrm{C}$ for $40 \mathrm{sec}$.

Cell growth assay. OV2008 cells (pSRG-shCon and pSRG-shPml) were grown in 96-well plates for $24 \mathrm{~h}$, and the number of cells in each well was $3 \times 10^{3}$. The proliferative activity was tested by MTT assay, followed by $4 \mathrm{~h}$ incubation of $20 \mu \mathrm{l}$ MTT solution ( $5 \mathrm{mg} / \mathrm{ml}$ in PBS). Absorbance was measured at $490 \mathrm{~nm}$. The experiment was repeated three times.

Clone formation experiment. After 24-h incubation, cells with a stable expression of pSRG-shCon and pSRG-shPml were collected by trypsinization to form monoplast suspension. The cells were counted, plated in $6-\mathrm{cm}$ culture dishes at $1 \times 10^{3}$ cells, and cultured for $10-15$ days at $37^{\circ} \mathrm{C}$ and $5 \% \mathrm{CO}_{2}$. The cells were stained with Coomassie brilliant blue, followed by three rinses in tap water and drying at room temperature. The number of clones (cell number $>50$ cells/colony) was counted, each with 4-5 replicates. The experiment was repeated three times.

Immunofluorescence. Cultured cells were seeded in 24-well plates with a glass bottom and continued to culture for $24 \mathrm{~h}$. The cells were washed with PBS and then fixed with $4 \%$ paraformaldehyde. The immobilized cells were then washed with PBS and permeabilized with $0.5 \%$ Triton X-100 (PBST). PBST containing 5\% bovine serum albumin was used as block buffer. After $1 \mathrm{~h}$ at room temperature, primary antibodies (PML, Santa Cruz Biotechnology, Santa Cruz, CA, USA; p-H2AX, Cell Signaling Technologies, Danvers, MA, USA; cleaved caspase-3, Cell Signaling Technology) and Alexa Fluor 594or 488-conjugated secondary antibodies (Molecular Probes; Jackson Immunoresearch Laboratories, Inc., West Grove, PA, USA) were used. The nuclei was observed by DAPI staining (DAPI; Vector Laboratories, Inc., Burlingame, CA, USA). Images were observed through a fluorescence microscope (Nikon Eclipse 80i; Nikon Corporation, Tokyo, Japan).

Western blot analysis. The proteins separated by SDS-PAGE were transferred to PVDF membranes (Millipore Corp., Bedford, MA, USA) and the membranes were incubated with blocking liquid (5\% non-fat dry milk) for $1 \mathrm{~h}$, and then probed with primary antibodies for $1 \mathrm{~h}$ at room temperature. After washing with PBST, the membranes were incubated with secondary antibodies labelled with horseradish peroxidase (Cell Signaling Technologies) for $1 \mathrm{~h}$ at room temperature, and the membranes washed with PBST. After hybridization reaction, ECL Western Blot chemiluminescence reagent kit (Amersham Biosciences, Uppsala, Sweden) was applied for developing. The primary antibodies that were used included: PML (dilution, 1:1,000; mouse no. sc-966;Santa Cruz Biotechnology), $\beta$-Actin (dilution, 1:1,000; Rabbit.no. 4970S), p-H2AX (dilution, 1:1,000; Rabbit.no. 9718), p-CHK1 (dilution, 1:1,000; Rabbit no. 2348), cleaved caspase-3 (dilution, 1:1,000; Rabbit. no. 9661) (Cell Signaling Technologies).

Immunohistochemistry. Ovarian tumor tissues were provided by the Second Hospital of Jiaxing and the Jiaxing Maternity and Child Health Care Hospital (Jiaxing China). Paraffin sections were deparaffinized by xylene (three times) and ethanol (three times), for 3 min each time, and the sections were rehydrated. After the sections were incubated in $0.3 \% \mathrm{H}_{2} \mathrm{O}_{2}$, antigen retrieval was carried out by $0.02 \mathrm{M}$ sodium citrate at $95^{\circ} \mathrm{C}$ for $15 \mathrm{~min}$. Ovarian tumor tissues were incubated with blocking liquid and probed with PML (dilution, 1:1,000; mouse. no. sc-966; Santa Cruz Biotechnology), and then washed with PBST. The membranes were incubated 
A

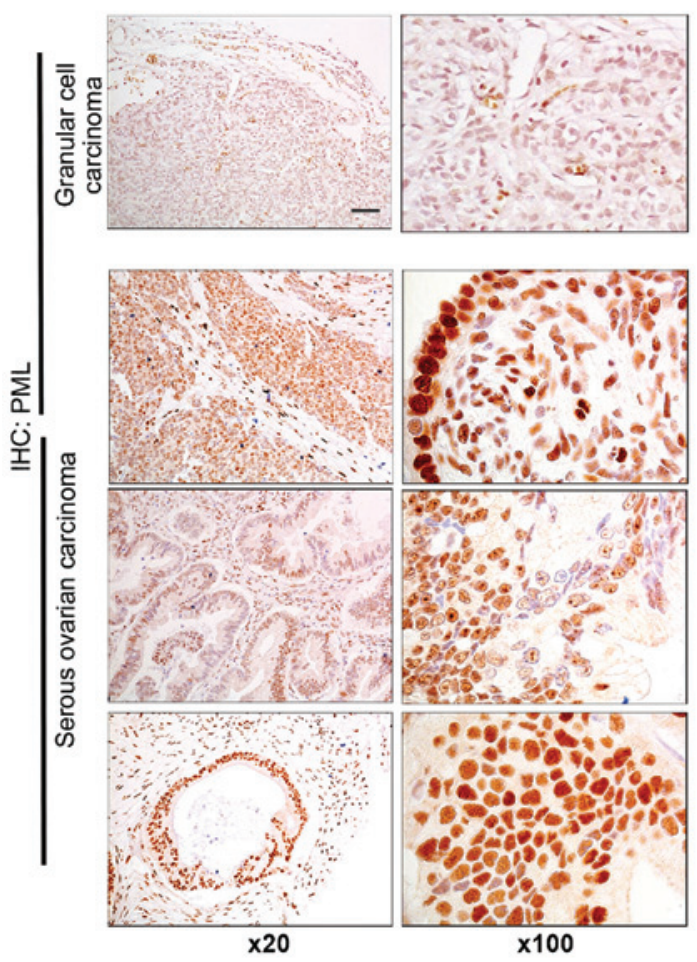

B
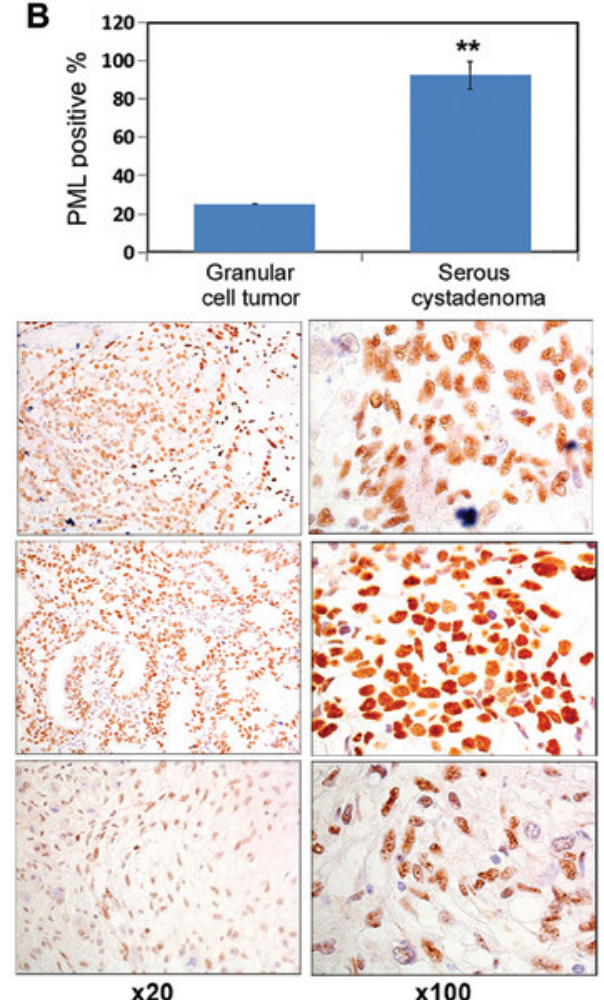

Figure 1. Promyelocytic leukemia (PML) expression patterns in human ovarian cancer tissues detected by immunohistochemistry (IHC). (A) IHC results for PML expression in human ovarian cancer tissues (serous ovarian carcinoma) and granular cell carcinoma tissues (magnification, $\mathrm{x} 20$ and $\mathrm{x} 100$ ). (B) The number of positive cells in serous ovarian carcinoma tissues was significantly higher than that of granular cell carcinoma. ${ }^{* *} \mathrm{P}<0.01$ vs. granular cell carcinoma.

with secondary antibodies for $30 \mathrm{~min}$ at room temperature. The ovarian tumor tissues were then washed with PBST and incubated with $\mathrm{ABC}$ solution for $30 \mathrm{~min}$ at room temperature. The tissues were again washed with PBST and developed using 3,3'-diaminobenzidine (DAB). After being dehydrated, the tissues were mounted with neutral resins.

Statistical analysis. The results were repeated three times. The analysis of variance and t-test were applied in comparing the intergroup difference of measurement data. GraphPad Prism statistical programs (GraphPad Prism, San Diego, CA, USA) was used. $\mathrm{P}<0.05$ was considered to indicate a statistically significant difference.

\section{Results}

PML is highly expressed in human ovarian cancer tissues. PML protein expression in human granular cell carcinoma tissue and human ovarian carcinoma tissue was detected by immunohistochemistry. As shown in Fig. 1A, significant PML staining intensity was detected in ovarian cancer tissue. The PML expression level was significantly increased in human ovarian carcinoma tissue, and the number of positive cells in human ovarian carcinoma tissue was significantly higher than that of granular cell carcinoma tissue (Fig. 1B).

Establishment and detection of stable cell lines with PML silencing. We used EcoRI and XhoI to construct and identify double-digested vectors. We successfully constructed pSRG-shPml and the control vector pSRG-shCon (Fig. 2A).
To detect the interference efficiency of shRNA, we transfected the vectors pSRG-shCon and pSRG-shPml into OV2008 cells. Total cell RNA was extracted after $24 \mathrm{~h}$. . RT-qPCR was used to detect the RNA interference efficiency. The shPml could markedly inhibit the expression of PML RNA in the cells (Fig. 2B). We also validated this result by immunofluorescence(Fig. 2C) and quantifcation of PML positive cells (Fig. 2D).

PML silencing induced inhibition of the proliferation and colony formation of ovarian cancer cells. After PML silencing, the number of viable OV2008 cells decreased (Fig. 3A), and MTT assay showed the cell proliferation ability decreased by $50 \%$ (Fig. 3B). At the same time, the ability of ovarian cancer cells to form monoclonal colonies decreased (Fig. 3C and D).

PML silencing promoted DNA damage in ovarian cancer cells. X-rays can induce PML to form foci in the nuclei of ovarian cancer cells (13). Using the immunofluorescence assay, PML was found to accumulate in the nucleus in response to $\mathrm{X}$-ray irradiation. With the increase in the irradiation dose, the number of foci increased gradually (Fig. 4A and C). We also found that the expression of $\mathrm{p}-\mathrm{H} 2 \mathrm{AX}$, a DNA damage protein, increased after $P M L$ silencing (Figs. $4 \mathrm{~B}$ and $5 \mathrm{~B}$ ). These results suggested that the subcellular localization of PML protein can be affected by radiotherapy, and decreased PML protein expression can induce DNA damage in ovarian cancer cells. PML silencing promoted apoptosis of ovarian cancer cells. The expression of the apoptosis protein cleaved caspase-3 increased over $24 \mathrm{~h}$, peaking $48 \mathrm{~h}$ after $P M L$ silencing (Fig. 5A and B). 

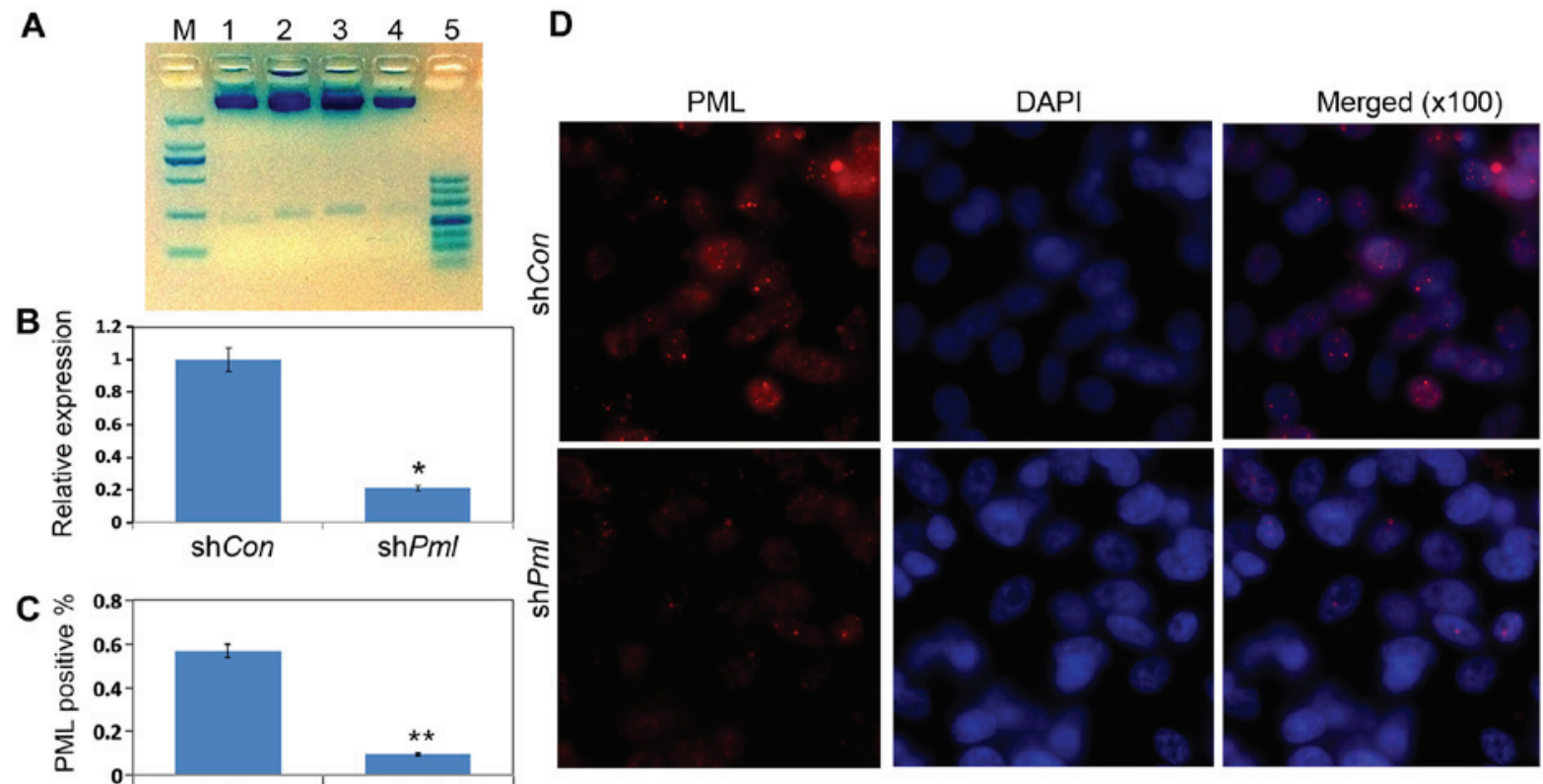

Figure 2. RT-qPCR and immunofluorescence results for the effects of promyelocytic leukemia $(P M L)$ silencing by RNA interference. (A) Restriction enzyme digestion analyses of the plasmids. Different plasmids were extracted and separated by $2.5 \%$ agarose gel. M, 2,000 bp DNA marker; 1, pSRG/XhoI, EcoRI; 2, pSRG-shCon/XhoI, EcoRI; 3-4, pSRG-shPml/XhoI, EcoRI; 5, 500 bp DNA marker. (B) OV2008 cells were transfected with pSRG-shCon and pSRG-shPml; total mRNAs were isolated $24 \mathrm{~h}$ after transfection. RT-qPCR for Pml mRNA expression levels in cultured cells. (C) Quantification of PML-positive cells.

(D) Immunofluorescence analysis for PML protein expression levels. Red, PML; blue, DAPI (magnification, x100).

A
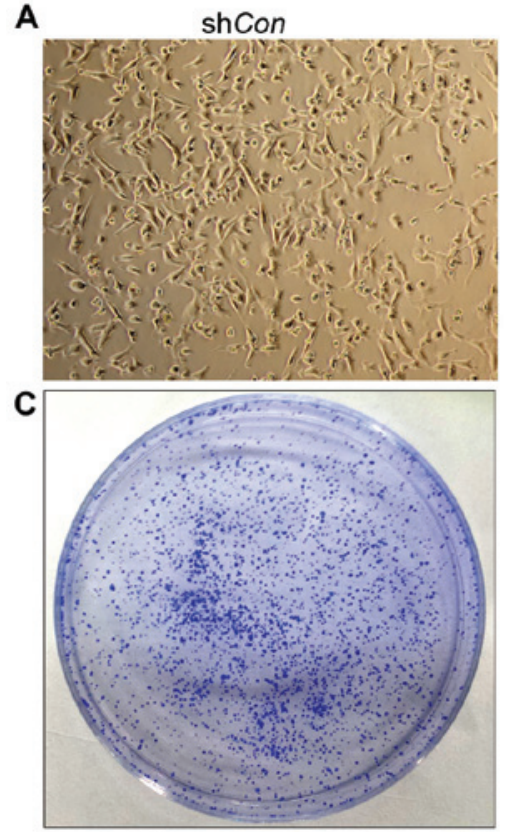
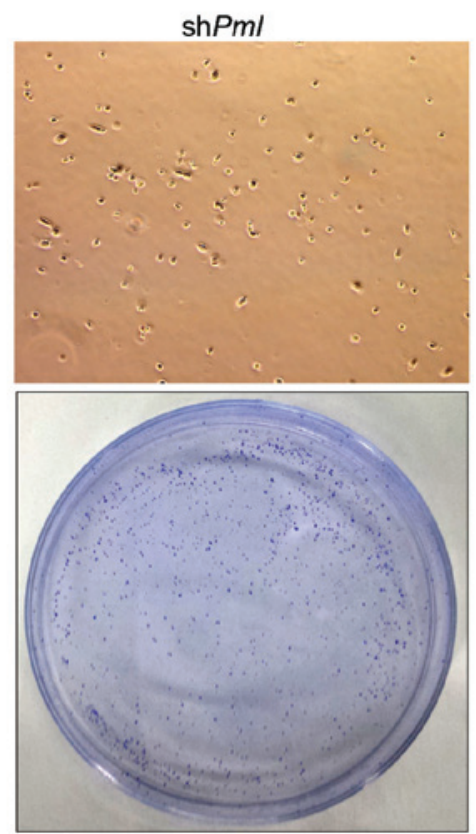

B

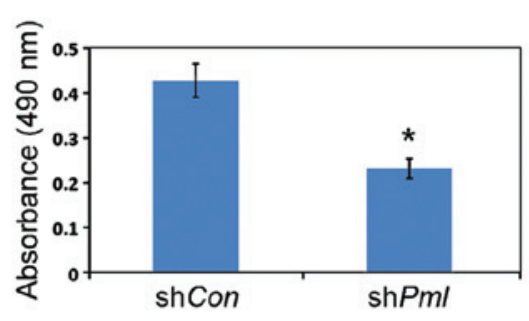

D

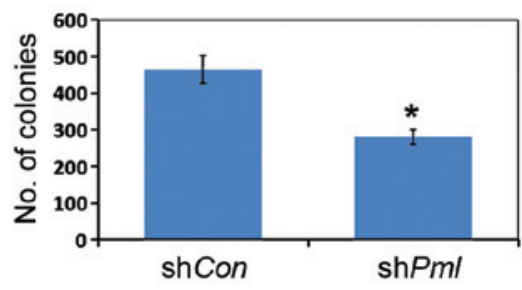

Figure 3. Promyelocytic leukemia $(P M L)$ silencing inhibited ovarian cancer cell proliferation and colony formation. (A) We observed $1 \times 10^{5}$ cells in 12 -well plates (magnification, x200) for $72 \mathrm{~h}$. (B) Cells were seeded in 96 -well plates $\left(3 \times 10^{3}\right.$ cells/well) for $72 \mathrm{~h}$ and then assessed by the MTT assay; $\mathrm{n}=3$, $\mathrm{P}<0.05 \mathrm{vs}$. shCon (C) Colony-formation assay for OV2008 cells with pSRG-shCon and pSRG-shPml. (D) Colony numbers were counted on day 15 after culture; $\mathrm{n}=3$, "P<0.01 vs. shCon.

\section{Discussion}

PML is an important part of the PML-NB structure and can recruit more than 30 different proteins, including Daxx, ATRX, and small ubiquitin-like molecules such as SUMO to the PML-NB region $(14,15)$. PML acts as a tumor suppressor and is involved in proliferation, apoptosis, senescence, DNA damage and angiogenesis in tumors (16). Numerous studies have demonstrated PML involvement in the regulation of apoptosis (17). Studies show cells from $\mathrm{PML}^{-/}$mice showed a greater resistance to apoptosis activated by either intrinsic or extrinsic apoptotic pathways compared with wild type, such as 
A

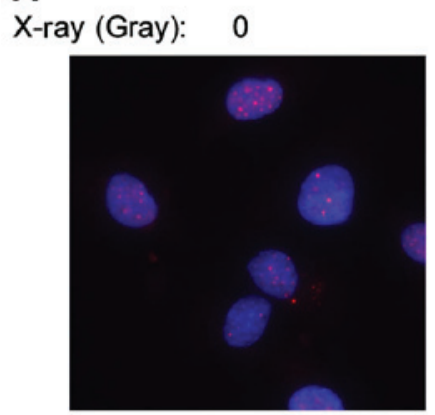

B

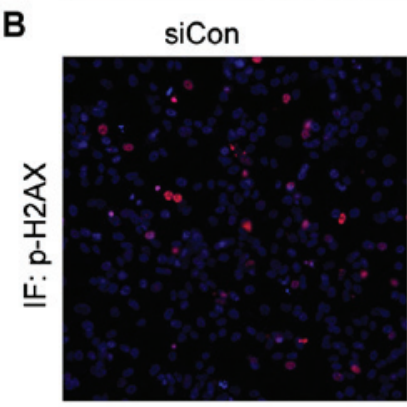

2

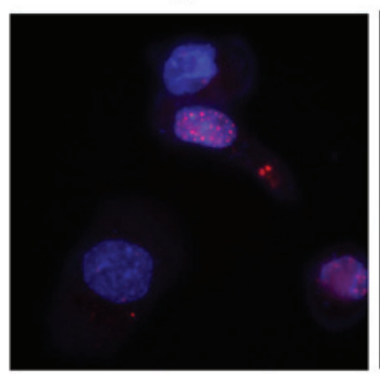

siPml

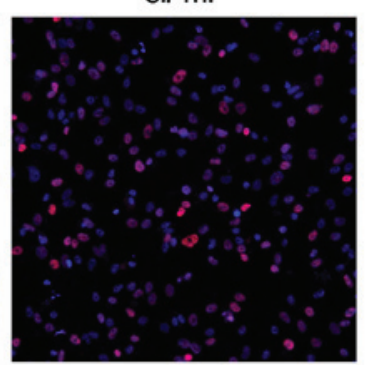

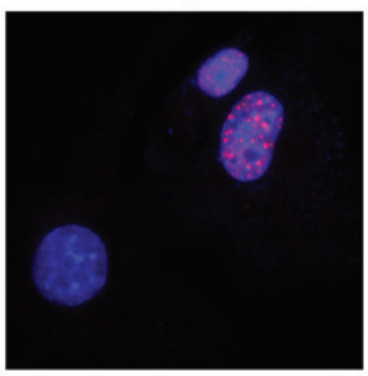

C

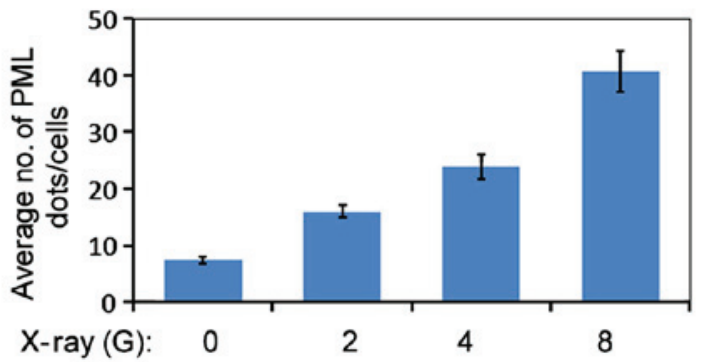

Figure 4. Promyelocytic leukemia (PML) expression in ovarian cancer cells in response to DNA damage insults. (A) Immunofluorescence results for the dose-dependent induction of nuclear PML foci formation by X-ray irradiation $(0,2,4$ and 8 Gray) in OV2008 cells. (B) Immunofluorescence results for p-H2AX with pSRG-shCon and pSRG-shPml. (C) Quantification of PML foci in nuclei after X-ray irradiation at the indicated time-points.

A

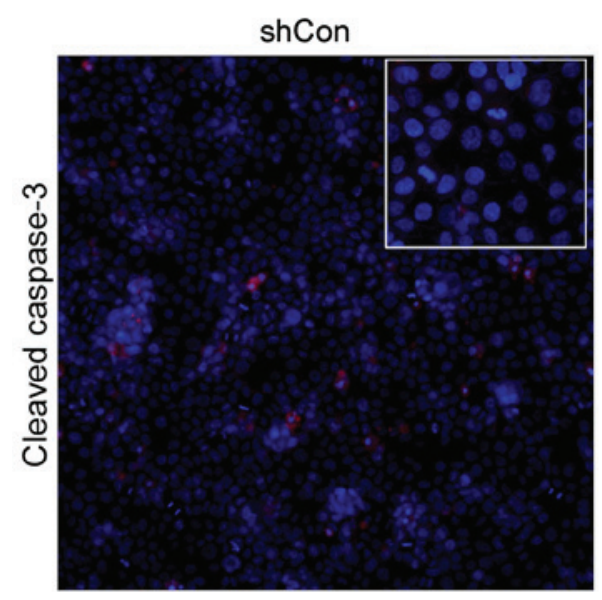

B

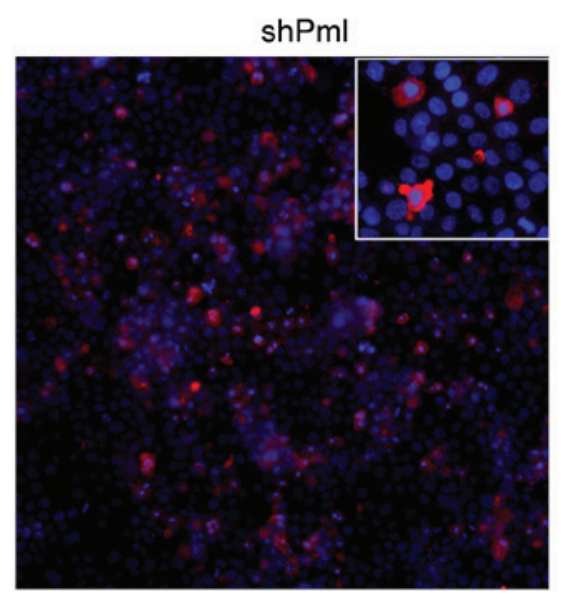

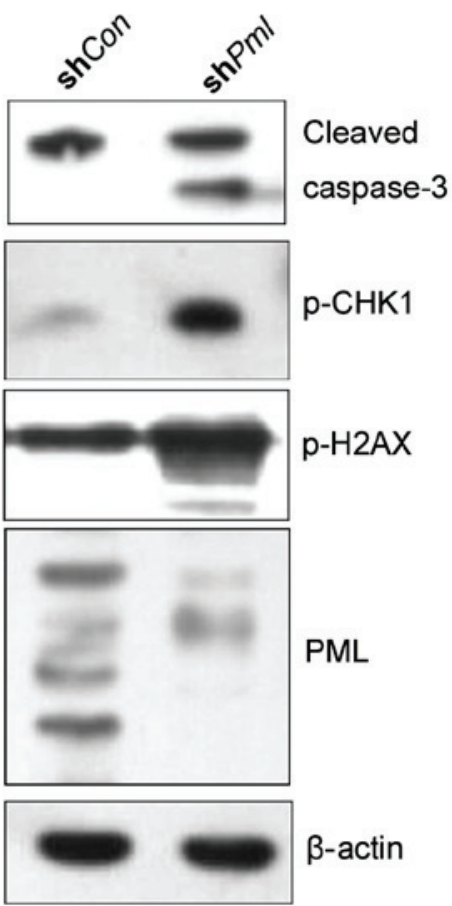

Figure 5. Promyelocytic leukemia $(P M L)$ silencing induced ovarian cancer cell apoptosis. (A) Immunofluorescent staining of cleaved caspase-3 after RNA interference-mediated depletion of PML. (B) Western blotting results for p-H2AX, p-CHK1, PML, cleaved caspase-3, and $\beta$-actin after the knockdown of PML.

thymocytes and embryonic fibroblasts $(18,19)$. By regulating acetylation of p53, PML played a critical role in the cellular senescence of V-H-Ras-induction. As T-box transcription factor, TBX2 is an E2F target and regulates PML-induced senescence $(20,21)$. KLHL20, a BTB-family protein, targets the tumor suppressor PML and DAPK (death-associated protein kinase) to its kelch-repeat domain for ubiquitination and degradation. PML and DAPK stabilization has been found to be mediated by KLHL39, a negative regulator of Cul3-KLHL20 ubiquitin ligase, in the process of colon cancer metastasis (22).

Additionally, the p38-MNK1-PML network regulates TNF $\alpha$-induced apoptosis in breast cancer cells and $\mathrm{TNF} \alpha$-mediated inhibition of migration and capillary tube 
formation in endothelial cells (23). PML can also activate fatty acid oxidation (FAO) and promote the self renewal of hematopoietic stem cells (24). The PML-FAO pathway can promote survival and proliferation in breast cancer cells. A high PML expression level is related to the prognosis of breast cancer. Cell metabolism mediated by PML is related to asymmetric cell division and multipotency, and it can promote the survival of cancer stem cells. PML deficiency leads to an increased number of DNA lesions, which is accompanied by changes in histone signature. 53BP1, the p53-binding protein, is associated with DNA damage responses. 53BP1 protein has two mobile fractions with distinct diffusion in wild-type cells; however, these fractions are absent in PML-deficient cells. This phenomenon indicated that PML plays key roles in the local motion of 53BP1 NBs in response to irradiation (25).

Ovarian cancer is one of the highest mortality rates that causes more deaths than any other cancer of the female reproductive system (26). Multi-drug resistance of ovarian cancer cells towards chemotherapeutic drugs is the main reason for failure of chemotherapy (27). In order to improve ovarian cancer chemotherapeutic effects to chemotherapy and survival of women, further research to explore how to rise the chemotherapeutic efficacy of ovarian cancer cells is needed. However, the role of PML in the occurrence and drug resistance of ovarian cancer has not been explored extensively.

To investigate the effect of the PML on ovarian cancer cell proliferation, apoptosis and DNA damage, we assessed the expression of PML protein in human ovarian cancer tissue by immunohistochemical methods. The high PML levels in ovarian cancer led us to surmise that PML is involved in the occurrence and drug resistance of ovarian cancer. We constructed a eukaryotic expression vector for PML silencing (pSRG-shPml) and transfected ovarian cancer cells using the vector. Through the establishment of stable cell lines with PML silencing, we found PML to be involved in ovarian cancer cell proliferation and clone formation by cell growth assays and clone formation experiments. We induced DNA damage in ovarian cancer cells by irradiation and found that the number of PML-NBs in the nuclei were elevated gradually with increases in the radiation dose, suggesting that PML-NB nuclei are highly sensitive to DNA damage.

However, the underlying mechanism of this phenomenon requires further research. A decreased expression of PML can promote apoptosis, which preliminarily showed that PML plays an important role in the process of ovarian cancer cell apoptosis. With the loss of PML expression, DNA damage in ovarian cancer cells increased, and CHK1 and H2AX phosphorylation were significantly elevated. This suggests that PMLNBs are also involved in the repair of DNA damage in ovarian cancer cells. However, the exact mechanism underlying the DNA damage occurring in ovarian cancer remains to be ascertained. Our present results suggest the applicability of PML as an early diagnostic marker for ovarian cancers. Targeting the PML degradation pathway may therefore be a promising approach for anticancer therapy.

\section{Acknowledgements}

The present study was supported by the Experimental Animal Science and Technology program of Zhejiang Province Grants (grant no. 2017C37114), Science and Technology Bureau Project of Jiaxing (grant no. 2015AY23063), and a grant from the 12th Five-year Plan for University Key Academic Subject (Pharmacology), Zhejiang, China.

\section{References}

1. Dutrieux J, Maarifi G, Portilho DM, Arhel NJ, Chelbi-Alix MK and Nisole S: PML/TRIM19-dependent inhibition of retroviral reverse-transcription by Daxx. PLoS Pathog 11: e1005280, 2015.

2. Fagioli M, Alcalay M, Pandolfi PP, Venturini L, Mencarelli A, Simeone A, Acampora D, Grignani F and Pelicci PG: Alternative splicing of PML transcripts predicts coexpression of several carboxy-terminally different protein isoforms. Oncogene 7: 1083-1091, 1992.

3. Sahin U, de Thé H and Lallemand-Breitenbach V: PML nuclear bodies: assembly and oxidative stress-sensitive sumoylation. Nucleus 5: 499-507, 2014.

4. Bernardi R, Papa A and Pandolfi PP: Regulation of apoptosis by PML and the PML-NBs. Oncogene 27: 6299-6312, 2008.

5. Collins SJ: Retinoic acid receptors, hematopoiesis and leukemogenesis. Curr Opin Hematol 15: 346-351, 2008.

6. Jensen K, Shiels C and Freemont PS: PML protein isoforms and the RBCC/TRIM motif. Oncogene 20: 7223-7233, 2001.

7. Shen TH, Lin HK, Scaglioni PP, Yung TM and Pandolfi PP: The mechanisms of PML-nuclear body formation. Mol Cell 24: 331-339, 2006.

8. Duprez E, Saurin AJ, Desterro JM, Lallemand-Breitenbach V, Howe K, Boddy MN, Solomon E, de Thé H, Hay RT and Freemont PS: SUMO-1 modification of the acute promyelocytic leukaemia protein PML: Implications for nuclear localisation. J Cell Sci 112: 381-393, 1999.

9. Zhong S, Müller S, Ronchetti S, Freemont PS, DejeanA and Pandolfi PP: Role of SUMO-1-modified PML in nuclear body formation. Blood 95: 2748-2752, 2000.

10. Bernardi R and Pandolfi PP: Structure, dynamics and functions of promyelocytic leukaemia nuclear bodies. Nat Rev Mol Cell Biol 8: 1006-1016, 2007.

11. Wethkamp N and Klempnauer KH: Daxx is a transcriptional repressor of CCAAT/enhancer-binding protein $\beta$. J Biol Chem 284: 28783-28794, 2009.

12. Hofmann TG and Will H: Body language: The function of PML nuclear bodies in apoptosis regulation. Cell Death Differ 10: 1290-1299, 2003.

13. Pan WW, Zhou JJ, Liu XM, Xu Y, Guo LJ, Yu C, Shi QH and Fan HY: Death domain-associated protein DAXX promotes ovarian cancer development and chemoresistance. J Biol Chem 288: 13620-13630, 2013.

14. Salomoni P, Dvorkina M and Michod D: Role of the promyelocytic leukaemia protein in cell death regulation. Cell Death Dis 3: e247, 2012.

15. Van Damme E, Laukens K, Dang TH and Van Ostade X: A manually curated network of the PML nuclear body interactome reveals an important role for PML-NBs in SUMOylation dynamics. Int J Biol Sci 6: 51-67, 2010.

16. Chen RH, Lee YR and Yuan WC: The role of PML ubiquitination in human malignancies. J Biomed Sci 19: 81, 2012.

17. Chen RH, Lee YR and Yuan WC: The role of PML ubiquitination in human malignancies. J Biomed Sci 19: 81, 2012.

18. Guo A, Salomoni P, Luo J, Shih A, Zhong S, Gu W and Pandolfi PP: The function of PML in p53-dependent apoptosis. Nat Cell Biol 2: 730-736, 2000.

19. Wang ZG, Ruggero D, Ronchetti S, Zhong S, Gaboli M, Rivi R and Pandolfi PP: PML is essential for multiple apoptotic pathways. Nat Genet 20: 266-272, 1998.

20. Pearson M, Carbone R, Sebastiani C, Cioce M, Fagioli M, Saito S, Higashimoto Y, Appella E, Minucci S, Pandolfi PP, et al: PML regulates p53 acetylation and premature senescence induced by oncogenic Ras. Nature 406: 207-210, 2000.

21. Martin N, Benhamed M, Nacerddine K, Demarque MD, van Lohuizen M, Dejean A and Bischof O: Physical and functional interaction between PML and TBX2 in the establishment of cellular senescence. EMBO J 31: 95-109, 2012.

22. Chen HY, Hu JY, Chen TH, Lin YC, Liu X, Lin MY, Lang YD, Yen Y and Chen RH: KLHL39 suppresses colon cancer metastasis by blocking KLHL20-mediated PML and DAPK ubiquitination. Oncogene 34: 5141-5151, 2015. 
23. Hsu KS, Guan BJ, Cheng X, Guan D, Lam M, Hatzoglou M and Kao HY: Translational control of PML contributes to TNFa-induced apoptosis of MCF7 breast cancer cells and decreased angiogenesis in HUVECs. Cell Death Differ 23: 469-483, 2016.

24. Ito K, Carracedo A, Weiss D, Arai F, Ala U, Avigan DE, Schafer ZT, Evans RM, Suda T, Lee CH, et al: A PML-PPAR-ठ pathway for fatty acid oxidation regulates hematopoietic stem cell maintenance. Nat Med 18: 1350-1358, 2012.
25. Legartová $\mathrm{S}$, Sehnalová $\mathrm{P}$, Malyšková $\mathrm{B}$, Küntziger T, Collas $\mathrm{P}$, Cmarko D, Raška I, Sorokin DV, Kozubek S and Bártová E: Localized movement and levels of 53BP1protein are changed by $\gamma$-irradiation in PML deficient cells. J Cell Biochem 117: 2583-2596, 2016

26. Van Colombo N, Gorp T, Parma G, Amant F, Gatta G, Sessa C and Vergote I: Ovarian cancer. Crit Rev Oncol Hematol 60:159-179.

27. Siegel RL, Miller KD and Jemal A: Cancer statistics, 2015. CA Cancer J Clin 65: 5-29, 2015. 